\title{
La relación estudiante-docente en tiempos de cuarentena: desafíos y oportunidades del aprendizaje en entornos virtuales
}

\author{
The Student-Teacher Relationship in Times of Quarantine: Challenges and \\ Opportunities for Learning in Virtual Environment
}

\author{
Ignacio Soto-Córdova ${ }^{1}$
}

\begin{abstract}
RESUMEN
A raíz de la crisis sanitaria inaugurada por la pandemia del COVID-19 y la consecuente suspensión de las clases presenciales en todo Chile, equipos directivos, docentes y estudiantes se vieron enfrentados a continuar con los procesos de enseñanza y aprendizaje a través de diversas plataformas virtuales, no siempre obteniendo los mejores resultados, dada la multiplicidad de factores que dificultan tanto el acceso como la comunicación entre dichos agentes. El presente artículo presenta el caso de una actividad realizada para la asignatura de Educación Ciudadana, con estudiantes de $4^{\circ}$ año medio del Colegio Angol, institución educativa de carácter mixta, ubicada en dicha ciudad, capital de la provincia de Malleco. El diseño, construcción, monitoreo y evaluación de la actividad fueron ejecutados íntegramente en línea. Se busca plantear una reflexión en torno a la importancia que posee una significativa relación entre docente y estudiantes en entornos virtuales de aprendizaje, partiendo del supuesto de que cuando el/la docente lleva a cabo junto a sus estudiantes aquellos mismos proyectos que encomienda, la motivación de estos/as aumenta, cuestión fundamental en un contexto de encierro forzoso y de escaso contacto interpersonal.
\end{abstract}

Palabras claves: entornos virtuales; modelaje educativo; andamiaje educativo; motivación escolar; TIC; conectivismo.

\begin{abstract}
As a result of the health crisis inaugurated by the COVID-19 pandemic and the consequent suspension of face-to-face classes throughout Chile, principals, teachers and students were faced with continuing the teaching and learning processes through various virtual platforms, not always obtaining the best results given the multiplicity of factors that hinder both access and communication between these agents. This article aims to offer an example of an activity carried out with students in the 4th year of high school on a Citizenship Education course, whose design, construction,

\footnotetext{
${ }^{1}$ Profesor de Historia, Colegio Angol, Angol, Chile; Licenciado en Educación, Profesor de Estado en Historia, Geografía y Ciencias Sociales; andree.ignacio92@gmail.com.
} 
monitoring and evaluation was carried out entirely online. Along with this, it also seeks to enable reflection on the importance of a significant relationship between teacher and students in virtual learning environments, based on the assumption that if the teacher carries out the same projects with his students, their motivation increases, been this a fundamental issue in a context of forced confinement and little interpersonal contact.

Keywords: Virtual environments; educational modeling; educational scaffolding; school motivation; ICT; connectivism.

\section{Introducción: educación virtual en Chile en tiempos de coronavirus}

El 15 de marzo, el Gobierno de Chile decretó la suspensión de las clases en los establecimientos educacionales del país durante dos semanas, medida que terminaría por extenderse a los meses de abril y mayo. Esto a raíz de la expansión sostenida del COVID-19, virus de carácter pandémico que ya en aquel entonces registraba 156.400 casos a nivel mundial y alrededor de 7.074 víctimas fatales (Diario Sanitario, 2020).

El presente artículo busca posicionarse frente a una realidad ocurrida precisamente desde aquel lunes 16 de marzo: la necesidad de llevar adelante la implementación de prácticas pedagógicas en entornos virtuales de enseñanza y aprendizaje fuera de la institución escolar.

El Ministerio de Educación dispuso prontamente de una plataforma virtual, la cual, a modo de repositorio, permitía a padres, madres y estudiantes descargar material de estudio según el nivel correspondiente, así como también acceder a los textos escolares en formato PDF (Ministerio de Educación, 2020). Junto con ello, los establecimientos educacionales emplearon distintas plataformas de carácter e-learning para monitorear y cautelar la debida progresión curricular. De esta manera, un gran número de docentes desarrollaron, enviaron y supervisaron la ejecución de diversos recursos didácticos, aunque en un contexto de improvisación y profundo desconocimiento de la realidad estudiantil que se manifestaba afuera de cada colegio. Fue precisamente en este nuevo e inusual escenario que emergió una doble problemática: el estado de conexión y acceso a la red de internet de las familias chilenas y la incomprensión fáctica por parte de equipos directivos y docentes de cómo llevar a cabo prácticas educativas bajo la modalidad de una enseñanza y aprendizaje virtual. 
En relación a la primera problemática, cabe señalar que de acuerdo a los datos entregados por la Encuesta Suplementaria de Ingresos (ESI) que el Instituto Nacional de Estadística (INE) publicó en agosto de 2018 (Durán y Kremerman, 2019), el 50\% de las personas asalariadas en Chile gana menos de \$400.000 mensuales. Así mismo, solo el 20,2\% de la población gana más de $\$ 750.000$ líquidos al mes. Cabe preguntarse: ¿qué relación guarda esta información con el estado de conexión y acceso a la red de internet de las familias chilenas? Pues bien, así como estas cifras evidencian los acentuados niveles de inequidad salarial en nuestro país, también es posible establecer nexos entre la situación sociolaboral de muchas familias chilenas y la posibilidad real de disponibilidad y acceso a internet de un gran número de escolares chilenos/as, en un contexto acentuado tanto por la crisis sanitaria derivada del coronavirus como por la disminución simultánea de empleos y fuentes de trabajo efectivas para sus familias.

De esta manera, según los datos levantados por Paz Radovic (Radovic, 2020), 380 mil estudiantes de primero a cuarto medio a nivel nacional viven en zonas con un acceso a internet deficiente, se desarrollan en contextos socioeconómicos vulnerables o estudian en establecimientos educacionales que se encuentran en categorías de desempeño insuficientes (principalmente colegios y liceos de dependencia municipal). Esta cifra contrasta evidentemente con los datos entregados por la OCDE a mediados de 2017, cuando se sostuvo que el acceso a internet en Chile subió sustancialmente a un 87,5\%, superando el promedio de los países miembros que es de un 80\% (Gattavara, 2020).

En lo que respecta a la segunda problemática, relacionada con la incomprensión y desconocimiento por parte de los equipos directivos y docentes de las instituciones escolares en cuanto a la ejecución de lineamientos pedagógicos en entornos de carácter virtual, la situación que se inauguró a partir del 16 de marzo bien puede ser caracterizada bajo la siguiente triada: administrativamente inconexa, particularmente atomizada y procesualmente cambiante.

Administrativamente inconexa, en el sentido de que el Ministerio de Educación solo se limitó a enviar una serie de orientaciones para docentes y equipos directivos, que entregan recomendaciones técnicas y sugerencias acerca del modo en que los establecimientos 
educacionales pueden "gestionar la emergencia sanitaria", pero carecen de una estructura curricular sólida y contextualizada que contemple la múltiple realidad de los colegios chilenos.

Particularmente atomizada, ya que, al carecer los colegios de un lineamiento programático derivado desde el Ministerio, queda a disposición y criterio de los equipos directivos la forma en que se llevará a cabo el proceso de implementación de las sesiones virtuales y la trasmisión de conocimientos hacia los/as estudiantes desde sus casas. Ciertamente, aquel proceso no estuvo exento de dificultades y de desafíos.

Procesualmente cambiante, pues, debido al desconocimiento acerca de maneras efectivas de llevar a cabo prácticas pedagógicas en contextos virtuales, los colegios literalmente “experimentan” y "prueban” sus propias prácticas, evaluándolas semanalmente y ajustándolas en virtud del grado de efectividad que poseen a la hora de ser desarrolladas por los/as estudiantes.

Si nos atenemos a la información entregada por Radovic (2020), a comienzos de abril solo un $32 \%$ de los establecimientos educacionales encuestados declaraba estar implementando alguna modalidad de clase virtual. Dicha información se relaciona con el carácter atomizado del desarrollo de prácticas digitales de los colegios, en concordancia con lo expresado en la Figura 1, donde se aprecia que la mayoría de los establecimientos considerados en la encuesta se valen de plataformas propias para llevar a cabo sus proceso pedagógicos. Cabe destacar, por lo demás, que los establecimientos optan por herramientas en donde se conjuguen mecanismos de comunicación audiovisual con prácticas de transmisión oral (expositiva) de la información, a fin de incentivar de mejor manera el trabajo a distancia de los/as estudiantes en un contexto de por sí adverso. 


\section{Figura 1}

Encuesta La Tercera: ¿Qué plataformas están utilizando los establecimientos para realizar clases online?

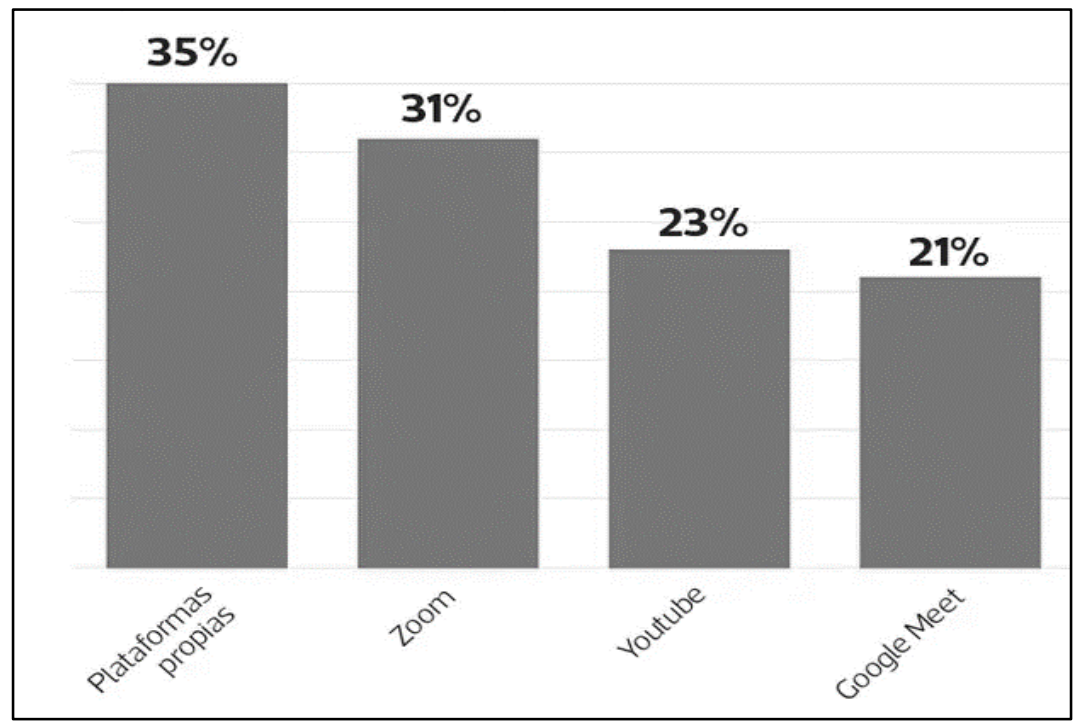

Nota. Tomado de Sin internet, a pulso: los escolares que se quedan atrás, por La Tercera, 2020, https://www.latercera.com

De acuerdo al mismo levantamiento realizado por Radovic (2020), un $80 \%$ de los establecimientos que se encuentran desarrollando prácticas de enseñanza virtuales señalan estar monitoreando la utilización del material pedagógico a través de algún sistema de gestión del aprendizaje. En tanto, alrededor de un $60 \%$ de dichas instituciones declara el envío de tareas a través de correos electrónicos como una forma de gestión al momento de transmitir información y deberes pedagógicos a los/as estudiantes y sus familias, según se puede apreciar en la Figura 2. En este gráfico también es posible evidenciar aspectos constitutivos de la primera problemática abordada en esta introducción, la que guarda relación con las falencias estructurales de acceso a internet y conectividad de un ingente número de hogares chilenos en la actualidad, cuestión que se condice con la necesidad de aquel $50 \%$ de casos en donde los/as docentes y sus respectivos colegios deben comunicarse vía llamadas telefónicas con las familias de sus estudiantes para transmitir información y cerciorarse de la receptividad de las actividades. 


\section{Figura 2}

Encuesta La Tercera: ¿Qué mecanismos de gestión está utilizando su establecimiento?

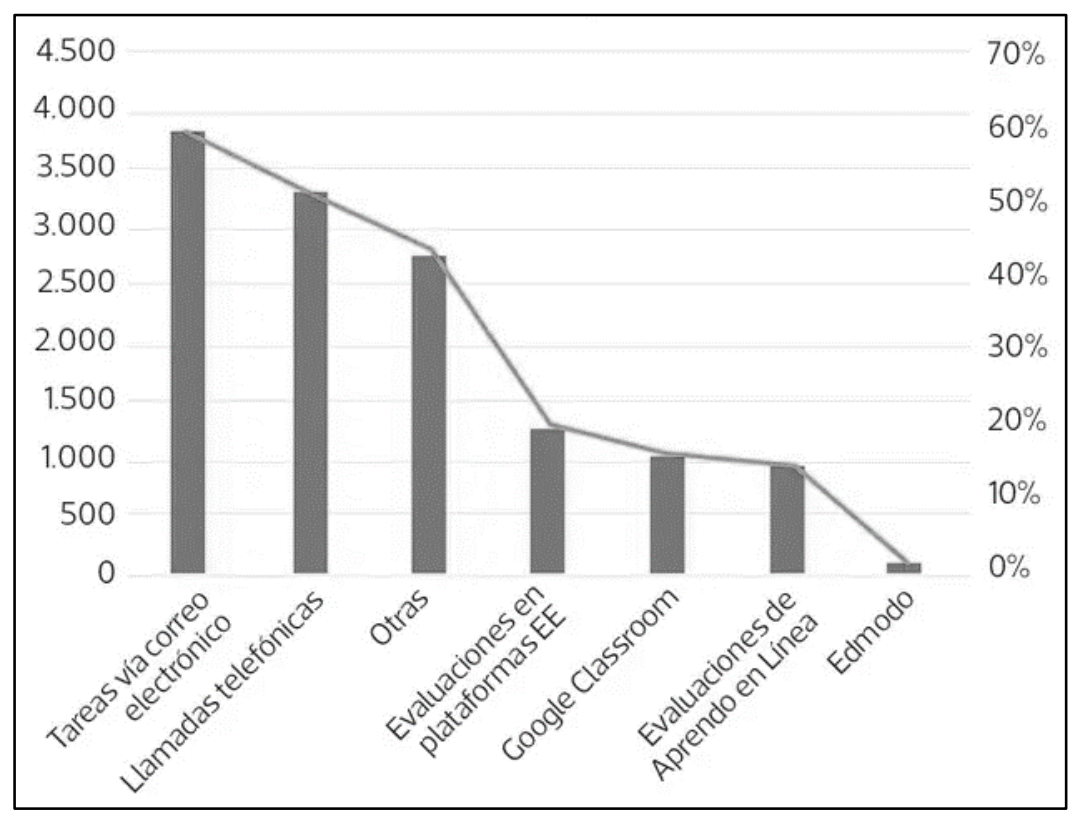

Nota. Tomado de Sin internet, a pulso: los escolares que se quedan atrás, por La Tercera, 2020, https://www.latercera.com

En concordancia con lo mencionado anteriormente, el presente artículo tiene por finalidad presentar un ejemplo metodológico de carácter empírico-experimental, pero con alcances teóricos, respecto a dos cuestiones fundamentales: por un lado, en cuanto al componente teórico, se propone reflexionar en torno a las nuevas perspectivas que reinterpretan la importancia de la relación docente-aprendiz en el proceso de aprendizaje recíproco que se produce entre ambos agentes, así como evaluar los alcances y oportunidades que ofrece la educación virtual en el contexto globalizado contemporáneo; por otro lado, y en cuanto al componente empírico, se busca ejemplificar lo anterior a través de la muestra de un trabajo que actualmente se encuentran realizando los estudiantes de $4^{\circ}$ año de enseñanza media del Colegio Angol, establecimiento educacional en donde se desempeña quien redacta este artículo. Dicha institución, de dependencia particular-subvencionada y de carácter mixto, se encuentra ubicado en la ciudad de Angol, capital provincial de Malleco, Región de la Araucanía. A raíz de la contingencia derivada de la crisis sanitaria del COVID-19, la 
actividad en cuestión ha tenido que ser ejecutada y guiada de forma remota, proceso educativo asistido mediante técnicas de educación virtual.

De esta manera, se pretende demostrar que cuando el/la docente asume los desafíos que encomienda a sus estudiantes, ajustándose incluso a los criterios evaluativos definidos por su persona, los/as estudiantes experimentan una sensación positiva de compenetración y sentido de mayor responsabilidad frente al trabajo que deben realizar, ya que se asume que tal empresa es de carácter colectivo y que, como tal, pueden contar con la ayuda de su profesor/a, más aún en el contexto de encierro y aislamiento forzado.

La estructura que adoptará este artículo es la siguiente: en primer lugar, se abordarán los aspectos de índole teórica y conceptual que sustentan la temática desarrollada en el escrito. En segundo lugar, se procederá a detallar la actividad de la asignatura de Educación Ciudadana del Plan de Formación Común, que fue ejecutada con estudiantes de $4^{\circ}$ medio de manera remota y completamente virtual. Finalmente, y en tercer lugar, se ofrecerá un espacio para evaluar la experiencia de aprendizaje realizada.

De esta forma, se espera que este trabajo permita arrojar luces a fin de situarse como un antecedente para continuar con las investigaciones referidas a la enseñanza virtual, siendo de utilidad para aquellos profesores y profesoras que, aun en contextos educativos adversos, diseñan estrategias que forman día a día a sus estudiantes.

\section{Marco teórico}

En el año 2015, Claudia Jaramillo y Jorge Chávez llevaron a cabo una exhaustiva revisión de la literatura especializada en el uso de TIC en contextos educativos, en un marco temporal de 10 años. De esta revisión cabe destacar tres importantes estudios.

El primero de ellos se refiere al uso efectivo de las TIC en estudiantes de educación media, trabajo realizado por Claro, Nussbaum, López y Díaz (2013). En este trabajo se sostiene que las prácticas de enseñanza-aprendizaje en escuelas chilenas asociadas al uso de herramientas virtuales han sido esporádicas y que aquello se explica por la falta de formación específica 
de los/as docentes, además de la falta de apoyo técnico-pedagógico para consolidar estos nuevos saberes.

En segundo lugar, se destaca el trabajo desarrollado por Claro et al. (2012), referido a las habilidades reales en el uso de TIC en estudiantes chilenos/as. Los resultados evidenciaron que la mayoría solo es capaz de resolver actividades relacionadas con el uso y búsqueda de información extraída desde la web, pero que existe una falencia en la capacidad de realizar tareas asociadas a la creación de representaciones propias en entornos virtuales.

Finalmente, y en tercer lugar, cabe considerar el estudio realizado por Cabrera (2007) acerca de las percepciones tanto de profesores/as como de estudiantes respecto al aprendizaje colaborativo mediado por computadoras móviles en entornos virtuales. Los resultados revelaron que para los/as estudiantes es importante el rol que juegan los/as profesores/as como agentes mediadores en el proceso de enseñanza, ya que dicho papel permite un mayor control y supervisión sobre las actividades desarrolladas por sus estudiantes.

De esta manera, Jaramillo y Chávez (2015) concluyen que además de existir poca evidencia que dé cuenta del uso efectivo de las TIC en el aula, la sola incorporación de las mismas no es condición ni garantía suficiente para lograr cambios en la educación.

\subsection{Fundamentos de la relación docente y aprendiz en entornos virtuales de aprendizaje}

A fin de consolidar las reflexiones y propuestas que se desarrollarán en el presente artículo, conviene referirse a algunas perspectivas actuales que abordan la relación educadoreducando (Muñoz, Conejeros, Contreras y Valenzuela, 2016) y que son necesarias para entender las prácticas pedagógicas, más allá de la mera transmisión de conocimientos. Nos referimos específicamente a la teoría del apego, a los estudios acerca de la motivación, y a elementos vinculados a las fortalezas y talentos de los/as estudiantes.

En cuanto al papel jugado por la teoría del apego, la bibliografía especializada sugiere que el/la educador/a debe asumir la responsabilidad de convertirse en una figura significativa 
para el proceso de desarrollo de sus estudiantes (Carbonero y Reoyo, 2011; López, Bilbao y Rodríguez, 2012). Cuando hablamos de "apego" en términos pedagógicos, nos referimos al hecho de que el/la docente debe generar condiciones de seguridad para sus estudiantes, en las que estos se sientan reconocidos/as y respetados/as, atendiendo a la posibilidad de equivocarse en su proceso de aprendizaje y contando con la compañía, escucha y contención por parte de su maestro/a, tanto en lo emocional como en lo formativo.

En relación al factor motivacional, este juega un papel clave dentro del proceso de aprendizaje, existiendo evidencia bibliográfica que permite relacionar la motivación con el grado de compromiso y rendimiento alcanzado por los/as estudiantes al interior de la escuela (Cerasoli, Nicklin y Ford, 2014). Ahora bien, refiriéndonos exclusivamente al docente, motivar significa generar, favorecer y estimular el "deseo de aprender" de los/as estudiantes (Viau, 2009), y para ello el/la docente necesariamente debe asumir tres importantes desafíos: el primero, alzarse como un "modelo de aprendiz", vale decir, modelar en sus estudiantes el gusto por aprender; el segundo, apropiarse a cabalidad y con el mayor grado de experticia posible de la disciplina que imparte, permitiendo que los/as estudiantes "hallen sentido" al contenido (Muñoz et al, 2016). Y, en tercer lugar, develar y transparentar el hecho de que el aprendizaje escolar constituye no solo una herramienta útil para comprender la realidad, sino que permite equiparar oportunidades de aprendizaje entre los/as estudiantes independiente de su origen social.

Finalmente, cabe destacar la perspectiva educacional centrada en el desarrollo de las fortalezas y los talentos de los/as estudiantes. Este enfoque sostiene que cada persona posee recursos necesarios que pueden ser movilizados hacia el éxito en muchos ámbitos de la vida (Anderson, 2004) y que un/a buen/a docente es quien permite a sus estudiantes ser conscientes de sus propios talentos, capacidades y fortalezas, permitiendo con ello que se enfrenten de manera óptima a los desafíos y dificultades que puedan tener al interior de la escuela.

En cuanto al componente tecnológico que define las prácticas de educación virtual, conviene destacar los aportes de la teoría del conectivismo y su relación con las perspectivas constructivistas en el ámbito educativo. 
El conectivismo es definido por Siemens (2004) como una teoría de aprendizaje para la era digital en un contexto globalizado y altamente tecnologizado. En la siguiente figura se pueden apreciar los principios constitutivos del conectivismo:

\section{Figura 3}

\section{Principios del conectivismo}

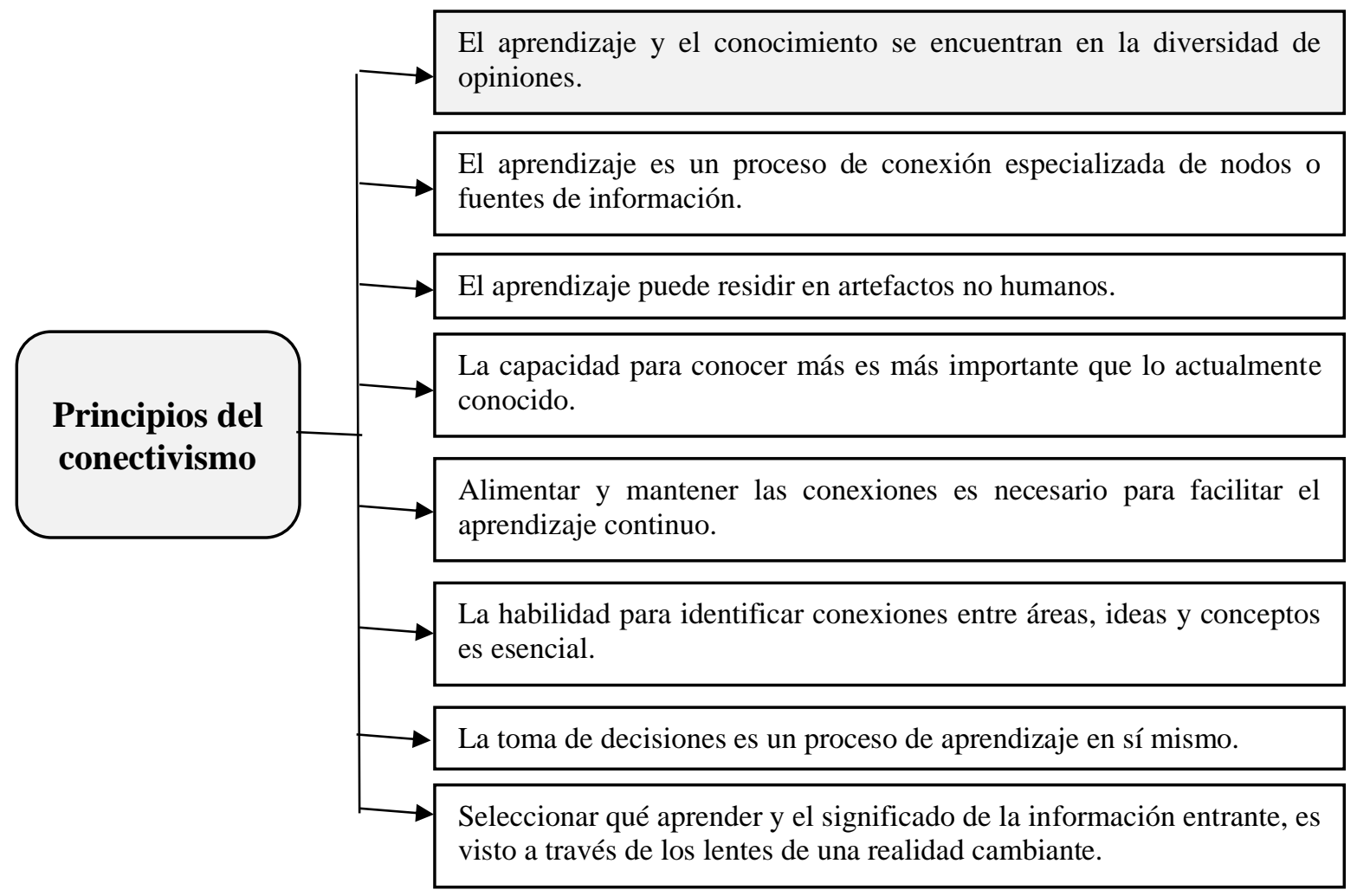

Para efectos prácticos del presente trabajo, destacaremos dos de los principios mencionados en la Figura 3: a) la habilidad para identificar conexiones entre áreas, ideas y conceptos; b) el aprendizaje y el conocimiento se encuentra en la diversidad de opiniones.

En relación al primer principio, cabe señalar que el conectivismo sostiene que la interacción entre los nodos ocurre al interior de redes, las cuales son definidas como conexiones entre identidades integradas en un todo, y que cualquier cambio termina por afectar a la red completa (Gutiérrez, 2002). Si se lleva esta afirmación al plano educativo, se constata que actualmente los/as estudiantes son agentes o "nodos" multifacéticos y que, para 
dar resolución a una problemática, establecen contacto con distintas fuentes. Estas no solo son repositorios inanimados desde donde se extraen datos, sino que también adquieren corporalidad y simbolismo, constituyendo espacios que van paulatinamente definiendo la identidad y la cultura de los/as estudiantes.

Si esto se traslada a un entorno virtual de aprendizaje, será posible evidenciar que a través de las redes sociales que se entretejen gracias a internet, las personas, de forma individual y colectiva, participan en ámbitos de (re)construcción del saber, estableciendo redes mediante las cuales ocurren procesos informales de aprendizaje que van más allá de la escuela (Spencer, 2004). El hecho de que los/as estudiantes sean "hijos/as de la globalización" permite a los/as especialistas definir el aprendizaje como algo caótico, continuo y complejo, ya que precisamente este ocurre en distintos "escenarios reducidos" (computadores y celulares), gracias a la flexibilidad e inmediatez que posibilita la red informática virtual.

Lo anterior adquiere sentido en cuanto al segundo principio ("el aprendizaje y el conocimiento se encuentra en la diversidad de opiniones"). Conviene aquí plantear una interrogante que permitirá establecer una relación entre conectivismo y constructivismo: ¿de qué manera la "diversidad de opiniones" que nutre el aprendizaje en un entorno remoto puede ser canalizada bajo fines pedagógicos de la mano de la teoría constructivista?

Marisol Hernández y Andrea Lizama (2015) plantean que la idea de learning by sharing o "aprender compartiendo" constituye un factor crítico de éxito en el proceso de aprendizaje virtual. Las investigadoras analizaron el modelo de enseñanza online de la Universidad de Artes, Ciencia y Comunicación (Chile), destacando que sus plataformas web se alimentan de las perspectivas constructivistas que ponen énfasis en el aprendizaje colaborativo y en los proceso subjetivos que se generan al interior de una sala de clases, prolongándose estos en un espacio de interacción virtual, siempre y cuando el/a docente sepa encauzar y estimular aquella "diversidad de opiniones" mencionada en la interrogante recién planteada.

En ese sentido, adquiere relevancia la definición de aprendizaje constructivista, la cual sostiene que este se fundamenta sobre dos aspectos centrales: el primero, la conexión que establecen los sujetos con situaciones de la realidad que los rodea; y el segundo, la consideración de que esta realidad ocurre en un contexto compartido, vale decir, que los 
seres humanos aportan y reciben representaciones de la realidad, compartiendo significados que a la larga se vuelven colectivos (Hernández, 2008).

Esto resulta lógico si se concibe el aprendizaje como fruto de la interacción social de los sujetos, miembros de una cultura y comunidad de origen (idea-fuerza del pensamiento de L. Vygotsky), cuestión que puede ser potenciada en contextos de educación virtual, favoreciendo el diálogo y el intercambio de ideas entre los/as estudiantes a través de las nuevas tecnologías digitales, más aún si estos son mediados y modelados por el/la docente.

De acuerdo a lo planteado por Cristina Del Mastro (2005), el centro de los procesos de enseñanza y aprendizaje está puesto en la actividad constructiva de el/la estudiante, concibiendo el sistema representado en la Figura 4 como un conjunto de interacciones mediadas siempre por el/la docente, aun cuando estas sean ejecutadas a distancia.

\section{Figura 4}

Triángulo interactivo de la educación a distancia

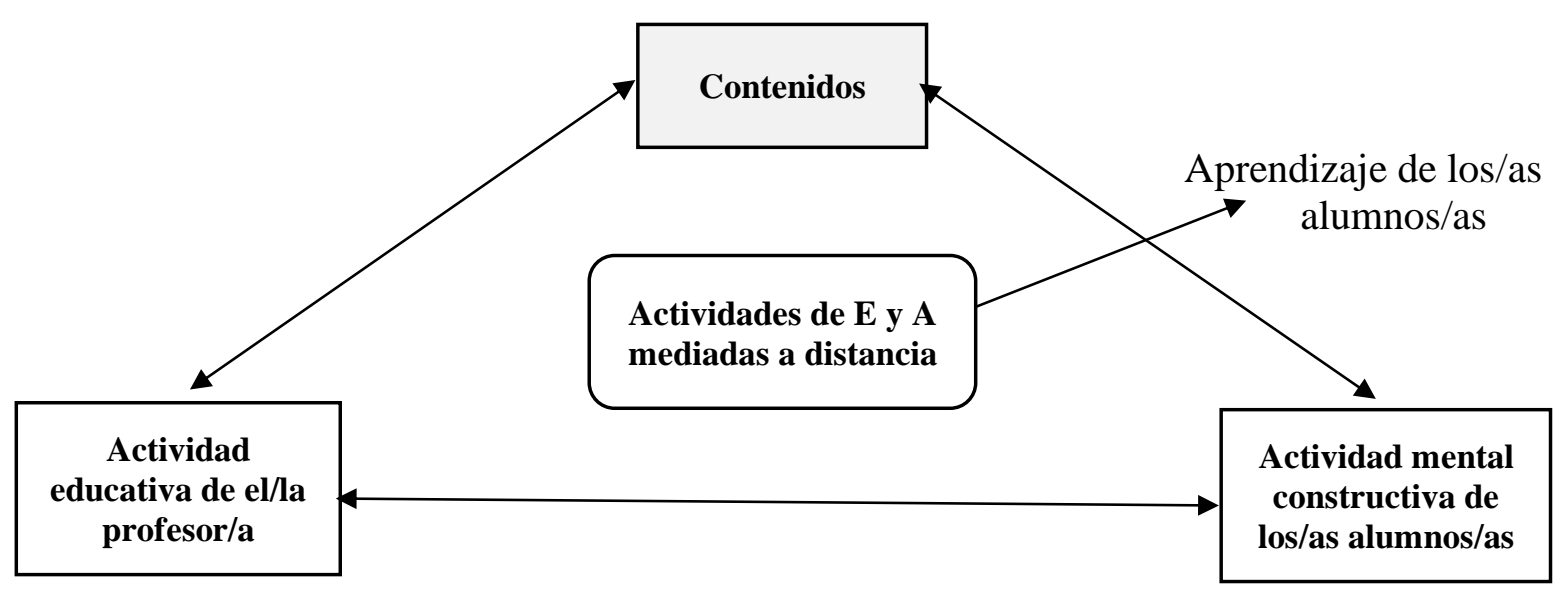

Nota. Tomado de Enseñanza estrategia en un contexto virtual. Un estudio de formación de tutores en educación contínua (p.30), de C. Del Mastro, 2005, Universidad Autónoma de Barcelona. 


\subsection{El rol docente en entornos virtuales de aprendizaje}

Nos referiremos, a continuación, a dos conceptos que derivan de dos perspectivas teóricopsicológicas que han nutrido abundantemente la investigación en torno al desarrollo humano y su educación: por un lado, el modelaje y, por otro lado, el andamiaje.

Albert Bandura, principal exponente de la teoría del modelaje, sostiene que "la mayor parte de la conducta humana se aprende por observación (...) de los demás, formando las reglas de conducta [propias]. Esta información es codificada y sirve en el futuro como guía de acción para las acciones posteriores" (Bandura, 1987, p.68).

El modelaje cumple una doble función en el aprendizaje de los/as estudiantes: puede fortalecer o inhibir una determinada conducta que ha sido previamente aprendida. Inhibe, cuando la persona que observa reduce la realización de la conducta que está siendo modelada, debido a las consecuencias negativas que observa en el modelo. Fortalece, cuando quienes observan aumentan la realización de una conducta al constatar su emulación por parte de otras personas (Contreras y Sepúlveda, 2015).

De esta manera, en un contexto de interacciones sociales tan enriquecedor como lo es la escuela, el/la docente juega un papel crucial a la hora de actuar como modelo para sus estudiantes, siendo importante que se alce como una figura significativa y profundamente imitable, cuestión que puede impactar de manera considerable en los aprendizajes de los/as estudiantes. Es por ello que los/as docentes, sea en cualquier contexto en donde se esté desarrollando el proceso de aprendizaje, deben ser conscientes de las conductas que modelan, en especial aquellas relacionadas a los valores, gestión de las emociones y resolución de conflictos, convirtiéndose en referentes positivos para sus estudiantes y sus futuras pautas de desarrollo (Mena, Jáuregui y Moreno, 2011).

En cuanto al concepto de andamiaje, este enfatiza que el/la docente no se centra exclusivamente en la transmisión de información, sino que más bien en el apoyo a la construcción del conocimiento, y en la facilitación y comprensión del mismo por parte de sus estudiantes (Duart y Sangrá, 2000). Recogiendo los aportes de Vygotsky sobre la "zona de desarrollo próximo" y gracias a los estudios realizados por Wood, Bruner y Ross (1976) 
en relación a la teoría del andamiaje, la figura de el/la tutor/a adquiere una importancia trascendental, ya que no solo modela con su acción educativa, sino que también sirve de apoyo para que el/la estudiante adquiera y elabore estrategias que le posibiliten adueñarse de conocimientos y habilidades, "aprendiendo a aprender" por sí mismo/a y generando espacios de interacción con otros/as estudiantes.

En síntesis, es posible dimensionar la complejidad de factores que intervienen en la relación entre docente y estudiante en un entorno virtual de aprendizaje, relación marcada por componentes que, si bien se encuentran presentes a diario y de maneras subyacentes en contextos educativos presenciales, adquieren especial y sutil relevancia al momento de desarrollar actividades académicas distanciadas.

\section{Marco metodológico}

En este apartado se procederá a identificar la actividad que, a la fecha de envío del presente artículo, se encontraban desarrollando los/as estudiantes de $4^{\circ}$ año de enseñanza media del Colegio Angol, en la asignatura de Educación Ciudadana del Plan de Formación Común. Esta fue anunciada a los estudiantes el 6 de abril y, por diversas decisiones de índole administrativa de la unidad técnico-pedagógica del establecimiento y a fin de no colapsar académicamente a los/as estudiantes, se ha venido ejecutando de manera procesual, marcada por intervalos de entregas parciales de "avances", vinculados a acciones derivadas de la tarea mayor.

La actividad planteaba el siguiente objetivo general: "Redactar un informe a partir de la selección de una situación problemática cotidiana y que guarde relación con una teoría política estudiada en las sesiones anteriores (republicanismo, comunitarismo y liberalismo), a fin de generar una propuesta de solución que permita evidenciar cómo la teoría en cuestión concibe la participación ciudadana a la hora de resolver conflictos de índole político-social”.

En cuanto a las habilidades a desarrollar, estas se agrupan en tres grandes ámbitos: investigación (enfatizando el análisis crítico de evidencias y los conceptos propios de la 
disciplina); pensamiento crítico (enfatizando el análisis de interpretaciones y perspectivas de diversas fuentes, así como en la elaboración de propuestas y juicios éticos de manera rigurosa); y comunicación (privilegiando la difusión escrita bajo cuño científico y académico de explicaciones y conclusiones fundamentadas, ajustadas a las normas y convenciones propias de la disciplina histórica) (Ministerio de Educación, 2019).

De esta manera, y a partir de la lectura de fuentes bibliográficas previamente entregadas, así como de la enseñanza de contenidos conceptuales abordados durante el mes de marzo, se procedió a configurar un detallado esquema de instrucciones a desarrollar procesualmente por los/as estudiantes y por el docente en cuestión.

Cabe señalar que la actividad, al ser parcelada en avances marcados por la ejecución de una determinada acción, permitió el monitoreo y la comunicación constante por parte del docente, en relación tanto al grado de consecución como a las posibles dificultades que pudieran presentar los/as estudiantes a lo largo del trabajo. Para compensar la falta de presencialidad, se dispuso de dos canales de comunicación y transmisión de información: el primero, la presencia del docente en un grupo de WhatsApp, diseñado especialmente para la realización del trabajo y, el segundo, el encuentro simultáneo semanal con los/as estudiantes a través de la plataforma virtual de "Appoderado" (https://appoderado.cl/). Esta constituye un sistema de mejoramiento escolar y de educación a distancia que el colegio utiliza regularmente para facilitar la comunicación masiva con los/as estudiantes, así como una plataforma que permite registrar evaluaciones, calendarizar actividades y ser un canal transmisivo y formal válido entre docentes y apoderados/as.

Cabe señalar que a los pocos días de declarada la suspensión de las clases presenciales, "Appoderado" lanzó con éxito una herramienta de educación a distancia llamada "Aula Virtual". En ella fue posible congregar tanto a los/as estudiantes como al docente de un curso y permitir a este realizar una sesión de enseñanza remota, cargando una presentación de Power Point y comunicándose de manera auditiva y escrita con sus estudiantes, quienes podían transmitir preguntas y zanjar dudas que iban surgiendo en el desarrollo de la actividad.

Es así como gracias a esta herramienta, el docente pudo concretar aspectos y necesidades referidas al andamiaje de acciones a realizar por parte de sus estudiantes, guiándolos en la 
consecución de sus actividades escolares y modelando a la vez su sentido de responsabilidad, transparentando el grado y la forma de avance del trabajo del propio docente, procurando mantener una motivación elevada que impida la deserción y abandono de dicha tarea por parte de los/as estudiantes.

En última instancia, se procedió a aplicar una encuesta de proceso a los estudiantes de los dos cursos que realizaban la actividad. Dicho instrumento buscó levantar información respecto a su percepción referida tanto a la relación docente-estudiante como a la forma en que se ha desarrollado la enseñanza en contextos de educación virtual. Los resultados de la misma son abordados en detalle en el siguiente apartado.

\section{Análisis de resultados}

De un total de 51 personas que componen el universo de estudiantes de los dos $4^{\circ}$ medios del establecimiento educacional en donde se llevó a cabo la actividad (4 medio "A": 25 estudiantes y $4^{\circ}$ medio "B": 26 estudiantes), la encuesta mencionada fue respondida por 47 estudiantes, lo cual equivale al $92 \%$ de la muestra total. A continuación, se procederá a realizar un análisis disgregado de los resultados obtenidos. En primera instancia, se abordarán los aspectos cuantitativos vinculados tanto a la relación docente-estudiante como a la educación virtual. En segunda instancia, se analizarán las dos preguntas abiertas desarrolladas por los/as estudiantes.

\subsection{DATOS DE CARÁCTER CUANTITATIVO}

La encuesta contiene siete preguntas con escalas valorativas, las cuales están agrupadas en dos secciones.

\subsubsection{SECCIÓN 1: RELACIÓN DOCENTE-ESTUDIANTES.}

La primera sección está conformada por cuatro preguntas, relativas a la relación docenteestudiantes. 
LA RELACIÓN ESTUDIANTE-DOCENTE EN TIEMPOS DE CUARENTENA: DESAFÍOS Y

OPORTUNIDADES DEL APRENDIZAJE EN ENTORNOS VIRTUALES / SOTO-CÓRDOVA

\section{Tabla 1}

Preguntas sección 1, sobre la relación docente-estudiante

\begin{tabular}{lcccc}
\hline & $\begin{array}{c}\text { Poco } \\
\text { Importante }\end{array}$ & $\begin{array}{c}\text { Medianamente } \\
\text { Importante }\end{array}$ & $\begin{array}{c}\text { Muy } \\
\text { Importante }\end{array}$ & Total \\
\hline Pregunta 1 & 6 & 3 & 38 & 47 \\
Pregunta 2 & 3 & 22 & 22 & 47 \\
Pregunta 3 & 9 & 13 & 25 & 47 \\
Pregunta 4 & 12 & 23 & 12 & 47 \\
\hline
\end{tabular}

De acuerdo a los datos recopilados, un $80 \%$ de los/as estudiantes reconoció como "muy importante y necesaria" la existencia de una relación cercana y confiable entre docente y estudiante (Figura 5), aspecto que contribuiría positivamente en el aprendizaje de los estudiantes.

\section{Figura 5}

Pregunta: ¿Es necesaria una relación cercana y confiable entre docente y estudiante a la hora de llevar a cabo una actividad de aprendizaje?

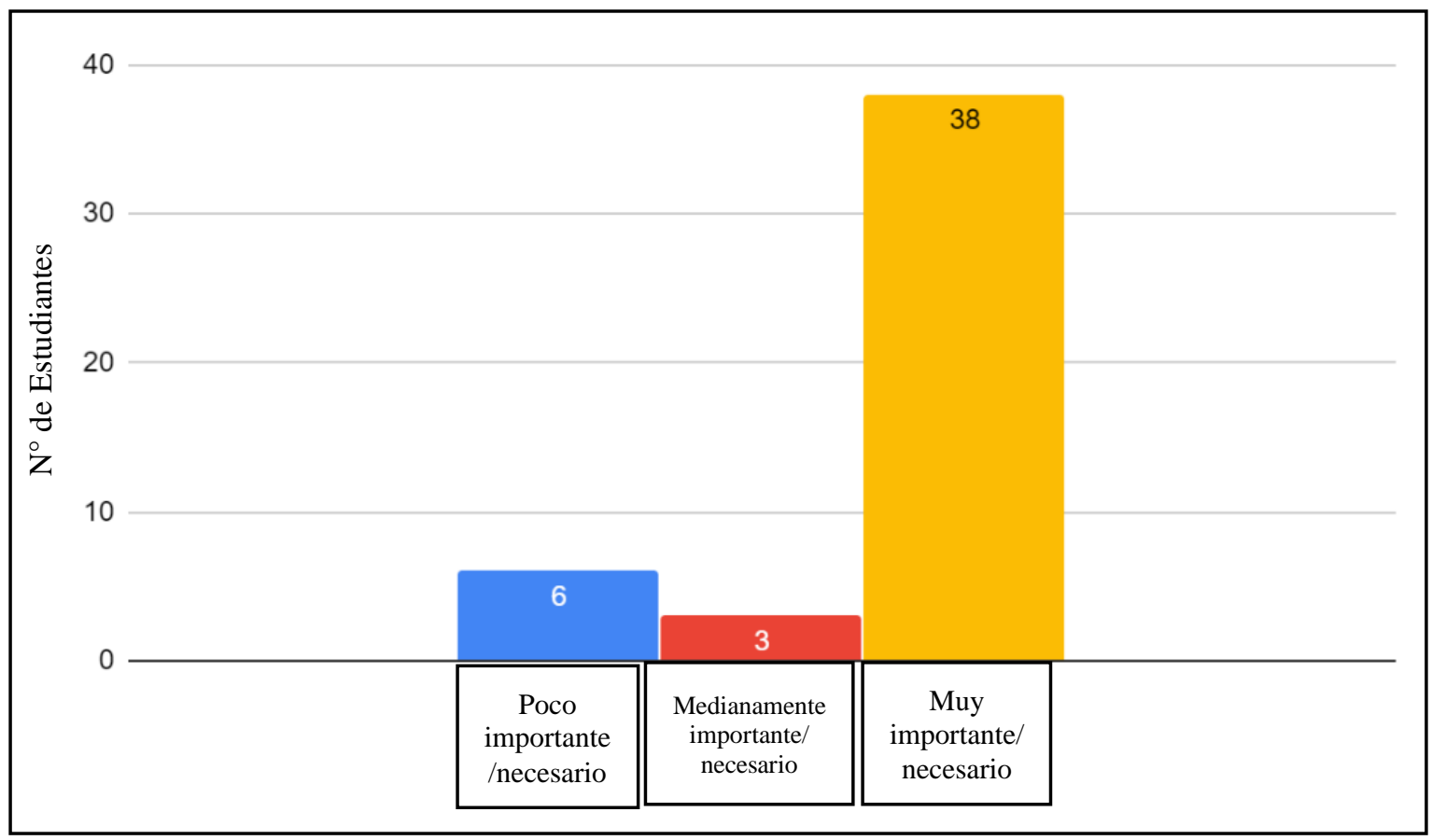


Por otro lado, como se puede ver en la Figura 6, un $47 \%$ de los/as estudiantes considera muy importante/necesario la relación existente entre motivación estudiantil y ejecución simultánea por parte del/la docente de las actividades que él/ella mismo diseñó, siendo un porcentaje muy menor el que lo percibe como poco importante.

\section{Figura 6}

Pregunta: El hecho de que el docente desarrolle el trabajo que él mismo diseñó, ¿incentiva la motivación de los estudiantes en su posterior realización?

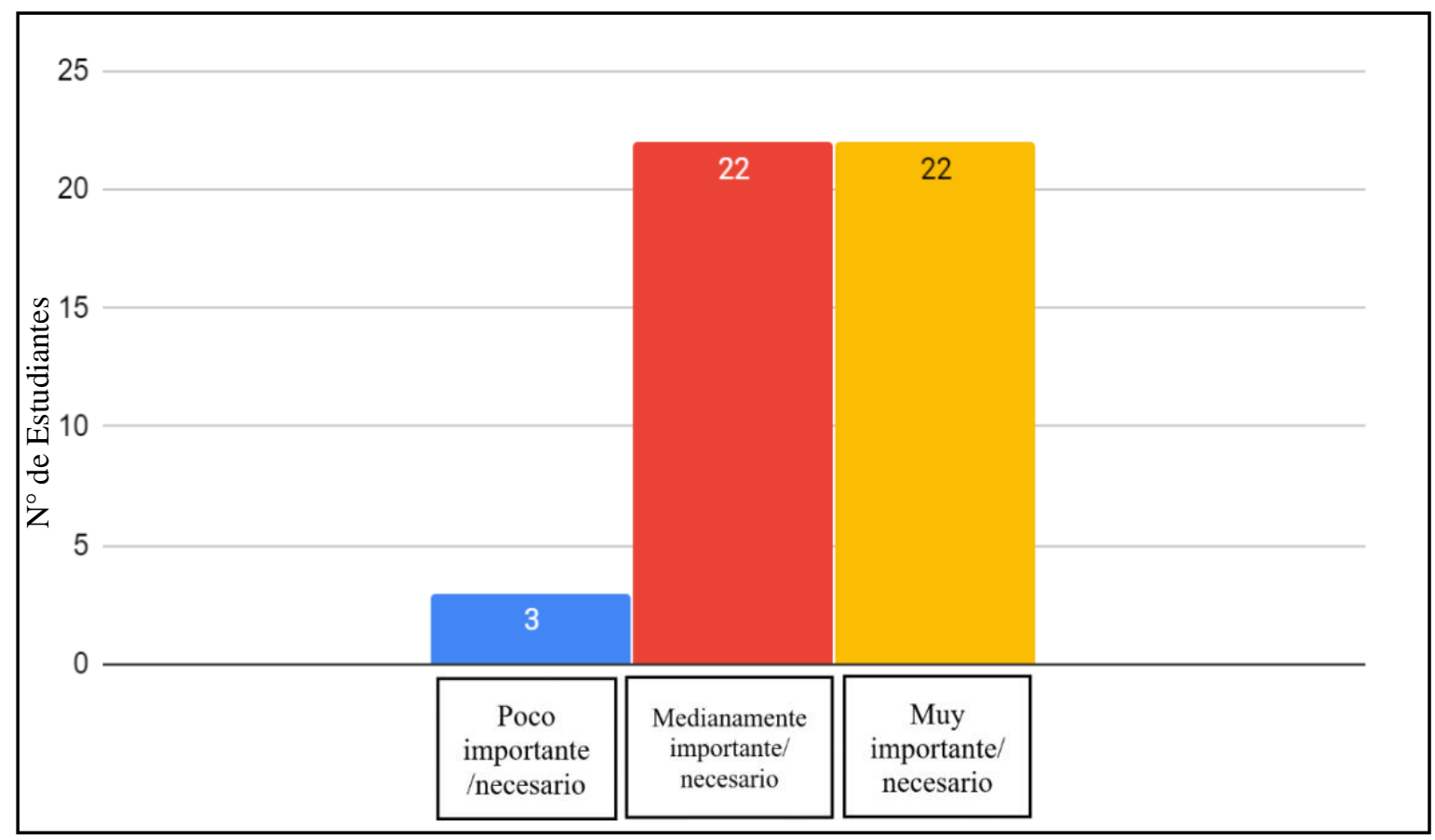

En cuanto a la tercera interrogante (Figura 7), un 53\% sostuvo que es conveniente que el/la docente conozca el desempeño cognitivo de sus estudiantes, atendiendo con ello de manera personalizada el nivel de logro de las actividades que estos realizan. 


\section{Figura 7}

Pregunta: ¿Conviene que el docente conozca el desempeño cognitivo de sus estudiantes, a fin de guiar de manera personalizada el nivel de logro de las actividades realizadas por estos?

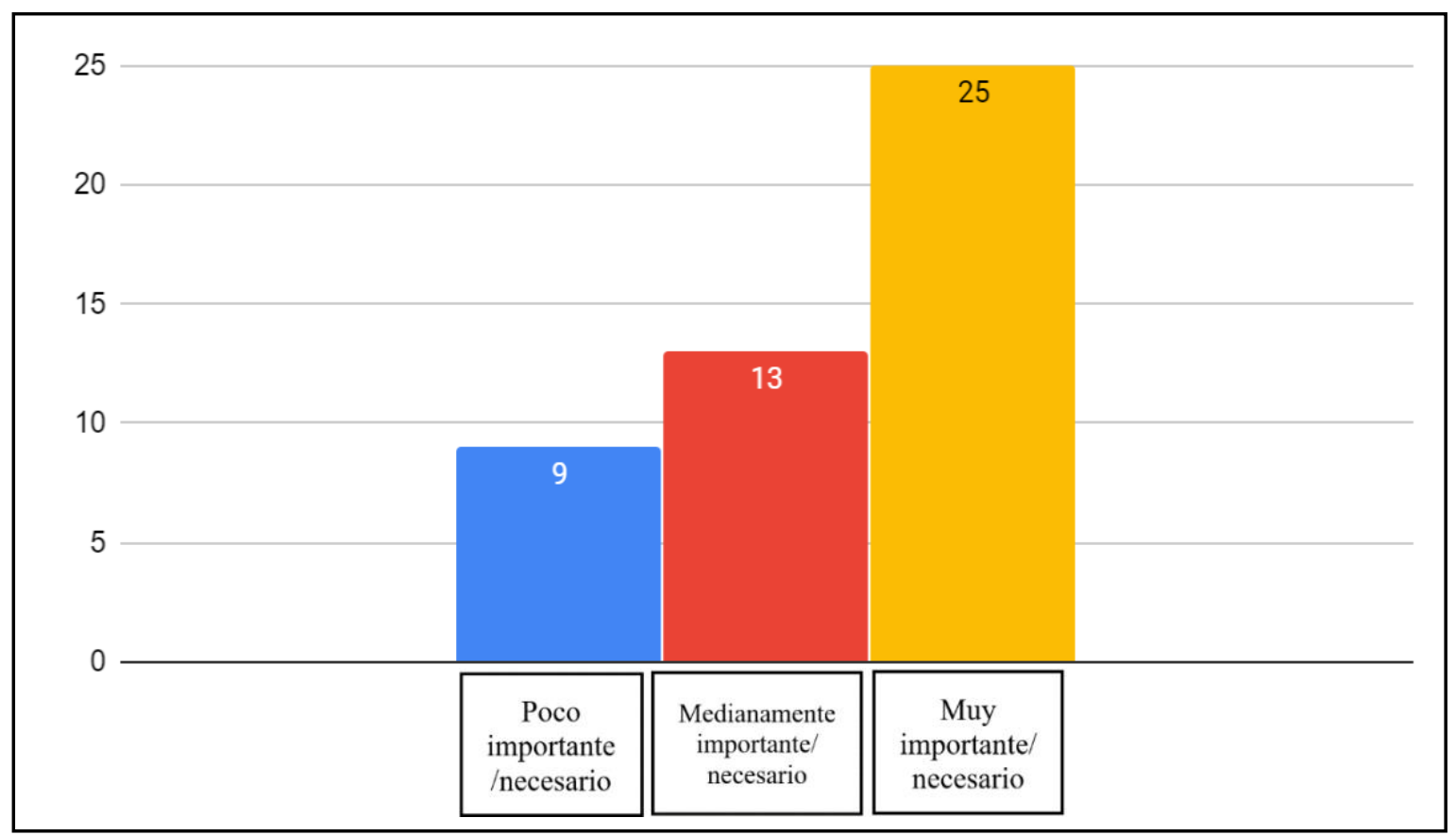

Finalmente, en relación al grado de periodicidad que debiese tener la comunicación del docente de asignatura con el/la docente jefe/a del curso, solo un $25 \%$ consideró este aspecto como "muy importante/necesario", en tanto que un mayoritario 48\% relativizó y restó importancia a dicho factor (Figura 8). 


\section{Figura 8}

Pregunta: ¿Es necesario que el docente de asignatura mantenga una comunicación periódica con el docente jefe del curso al que le hace clases, a fin de transmitirle cualquier eventualidad que ocurra en su curso?

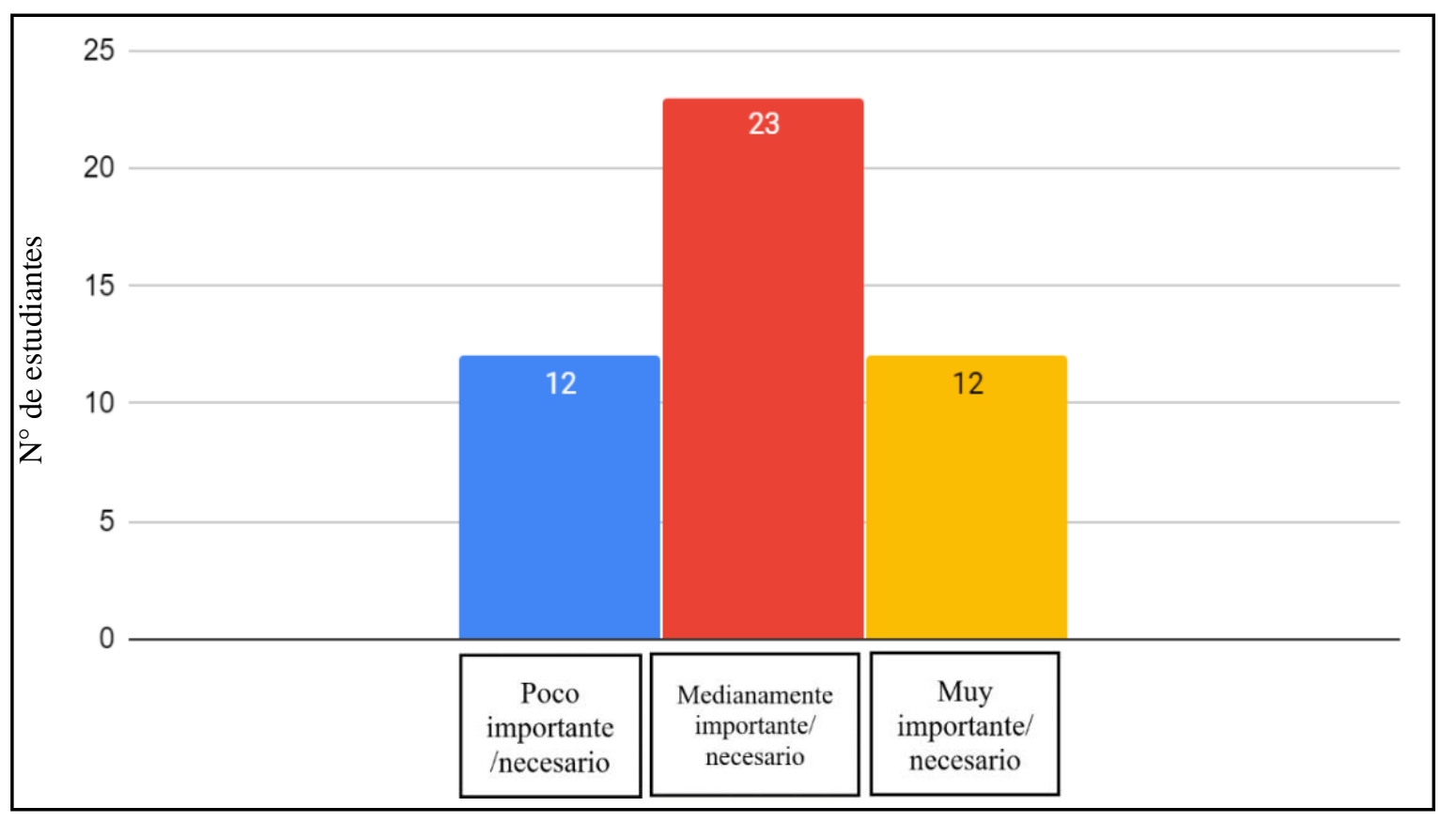

En relación a los datos entregados en esta primera sección, de índole cuantitativa, es posible evidenciar aspectos sostenidos en las bases teóricas del presente trabajo, sobre todo aquellos referidos a la importancia jugada por el apego y la motivación de los/as estudiantes, factores que se potenciarían gracias a la relación cercana basada en la confianza que debe existir entre docente y estudiante (Muñoz et. al., 2016). Dicha relación también permitiría sustentar el hecho de que la mitad de los/as estudiantes valida que el/la docente conozca el desempeño cognitivo de los mismos, para movilizar aquellos talentos y fortalezas que posibiliten el desarrollo de los/as estudiantes (Anderson, 2004).

Finalmente, se destaca que tres cuartas partes de los/as estudiantes se manifestó a favor del trabajo conjunto realizado con el/la docente, cuestión que es posible de ser ligada a los conceptos psicoeducacionales de modelaje (Contreras y Sepúlveda, 2015) y andamiaje (Wood et. al., 1976), ya que esta acción incentivaría en mayor medida el trabajo desarrollado 
por los/as estudiantes, manteniendo la motivación en un contexto de distanciamiento y sirviendo de guía y modelo para la actividad de los/as propios estudiantes.

\subsubsection{SECCIÓN 2: LA EDUCACIÓN VIRTUAL A DISTANCIA.}

En esta sección las tres interrogantes que se analizan se relacionan con aspectos referidos a la educación virtual a distancia:

\section{Tabla 2}

Preguntas de la sección dos, acerca de la relación docente-estudiante.

\begin{tabular}{lcccc}
\hline & $\begin{array}{c}\text { Poco } \\
\text { importante }\end{array}$ & $\begin{array}{c}\text { Medianamente } \\
\text { importante }\end{array}$ & $\begin{array}{c}\text { Muy } \\
\text { importante }\end{array}$ & Total \\
\hline Pregunta 1 & 3 & 13 & 31 & 47 \\
Pregunta 2 & 6 & 3 & 38 & 47 \\
Pregunta 3 & 9 & 9 & 29 & 47 \\
\hline
\end{tabular}

En lo que se refiere a la comunicación periódica y bidireccional que debiese existir entre docente y estudiante, un $65 \%$ de los/as encuestados/as consideró que es un factor muy importante y necesario en la ejecución de una actividad didáctica (Figura 9). En tanto, un 53\% señaló a WhatsApp como el medio de comunicación más efectivo y pertinente a la hora de sostener aquel contacto, seguido por un 34\% que valoró el aporte de las "clases virtuales" como instancias válidas de encuentro pedagógico (Figura 10). 


\section{Figura 9}

Pregunta: ¿El docente debe mantener comunicación periódica de carácter bidireccional con sus estudiantes en tanto dure el proceso de ejecución de la actividad encomendada?

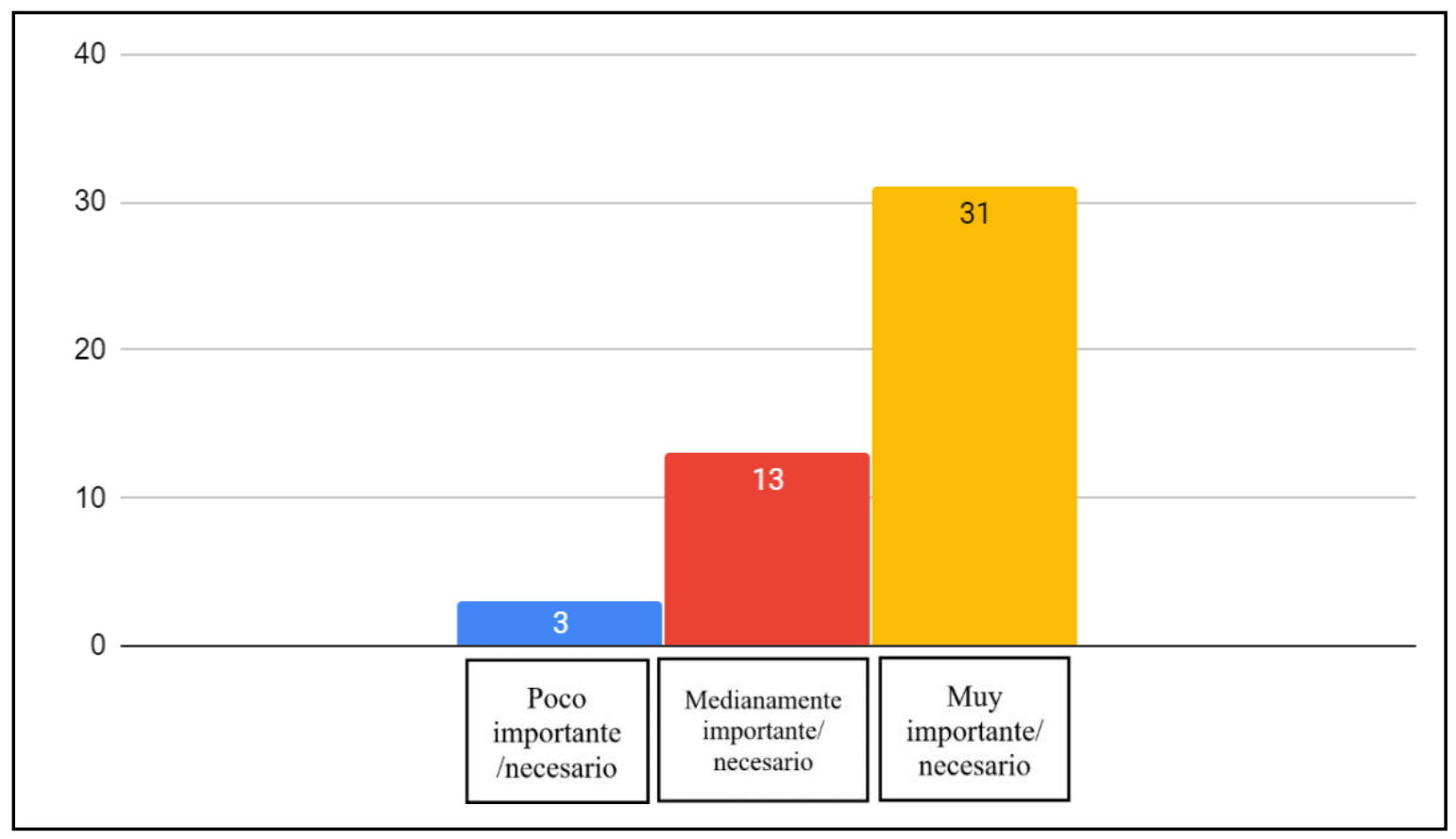

Figura 10

Pregunta: ¿Qué tipo de medio considera más pertinente?

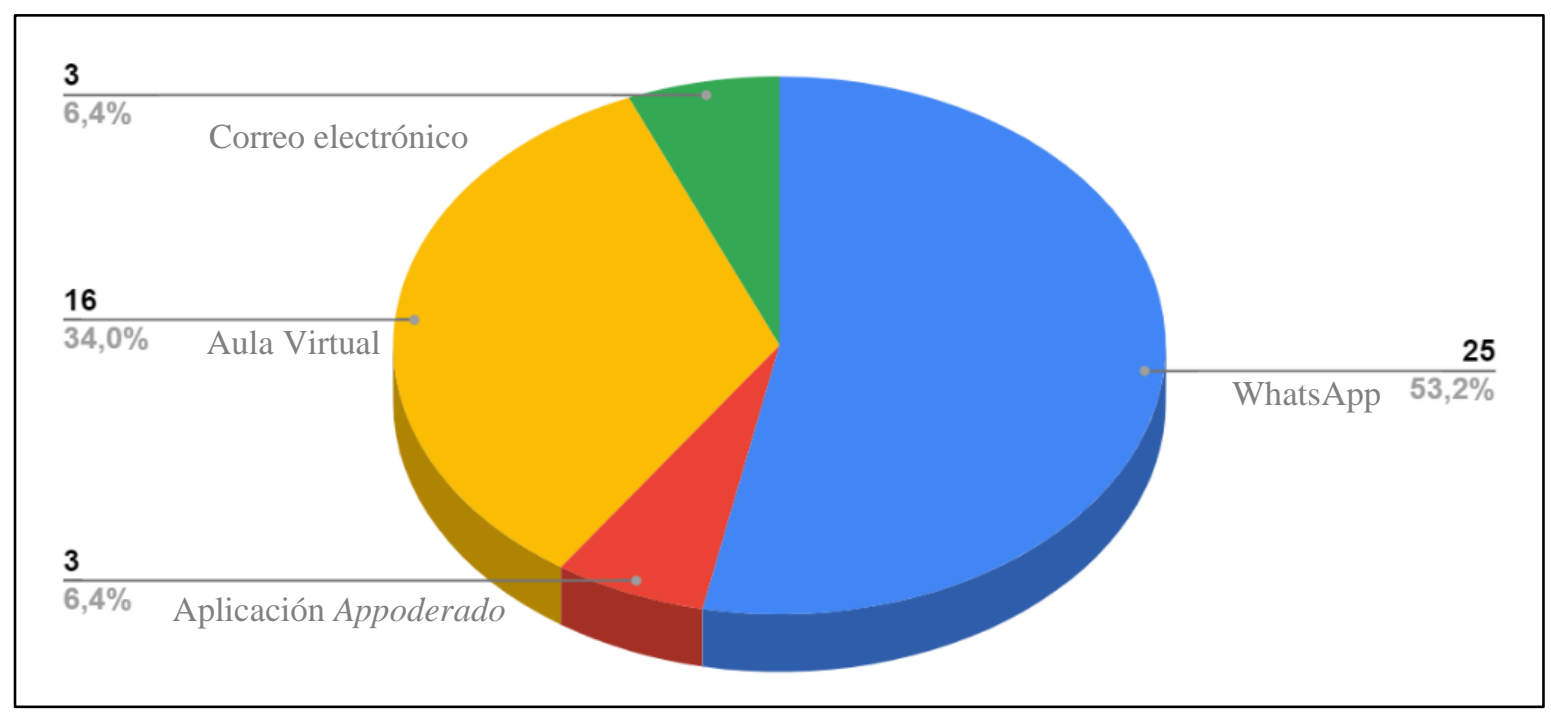


Asimismo, respecto a la conveniencia de realizar clases virtuales, un $65 \%$ de los/as estudiantes consideró estas instancias como momentos válidos para congregar a los miembros del curso e intercambiar información respecto al proceso de desarrollo de una actividad. En relación a ello, un $40 \%$ de los/as estudiantes declaró que debieran realizarse clases virtuales en un intervalo de frecuencia de 1 a 2 veces a la semana para concretar el requerimiento anterior (Figura 11).

\section{Figura 11}

Pregunta: ¿Qué intervalo de frecuencia de realización de las clases virtuales considera necesario para un proceso de aprendizaje efectivo?

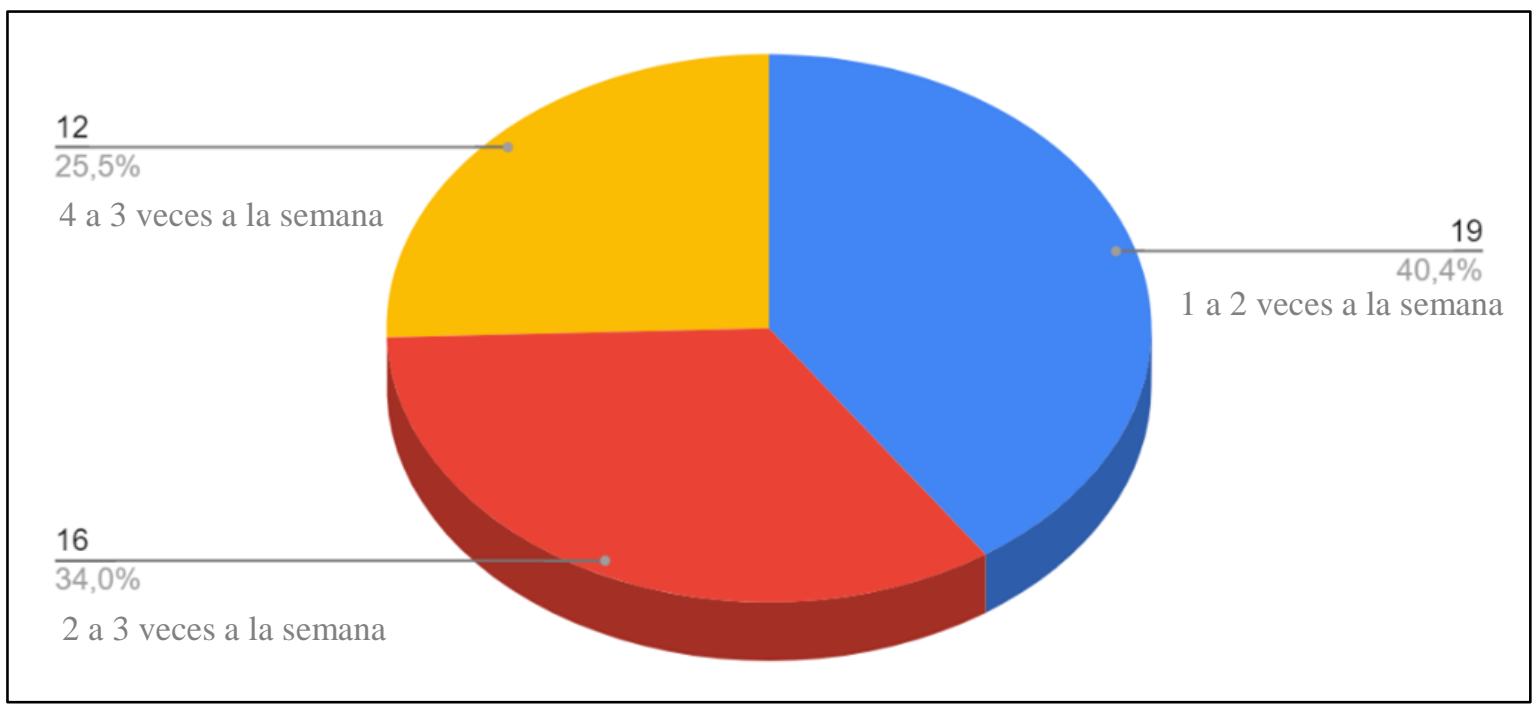

En última instancia y respecto a la interacción virtual entre compañeros (Figura 12), un $61 \%$ de los/las estudiantes consideró que es importante que, en ausencia del/la docente, exista intercambio de saberes y colaboración entre pares para enfrentar dificultades alusivas al proceso de aprendizaje. 


\section{Figura 12}

Pregunta: La interacción virtual a través de redes sociales entre compañeros de curso fuera de las clases presenciales, ¿constituye un componente para compartir conocimientos y resolver dificultades cuando no se encuentra presente el docente?

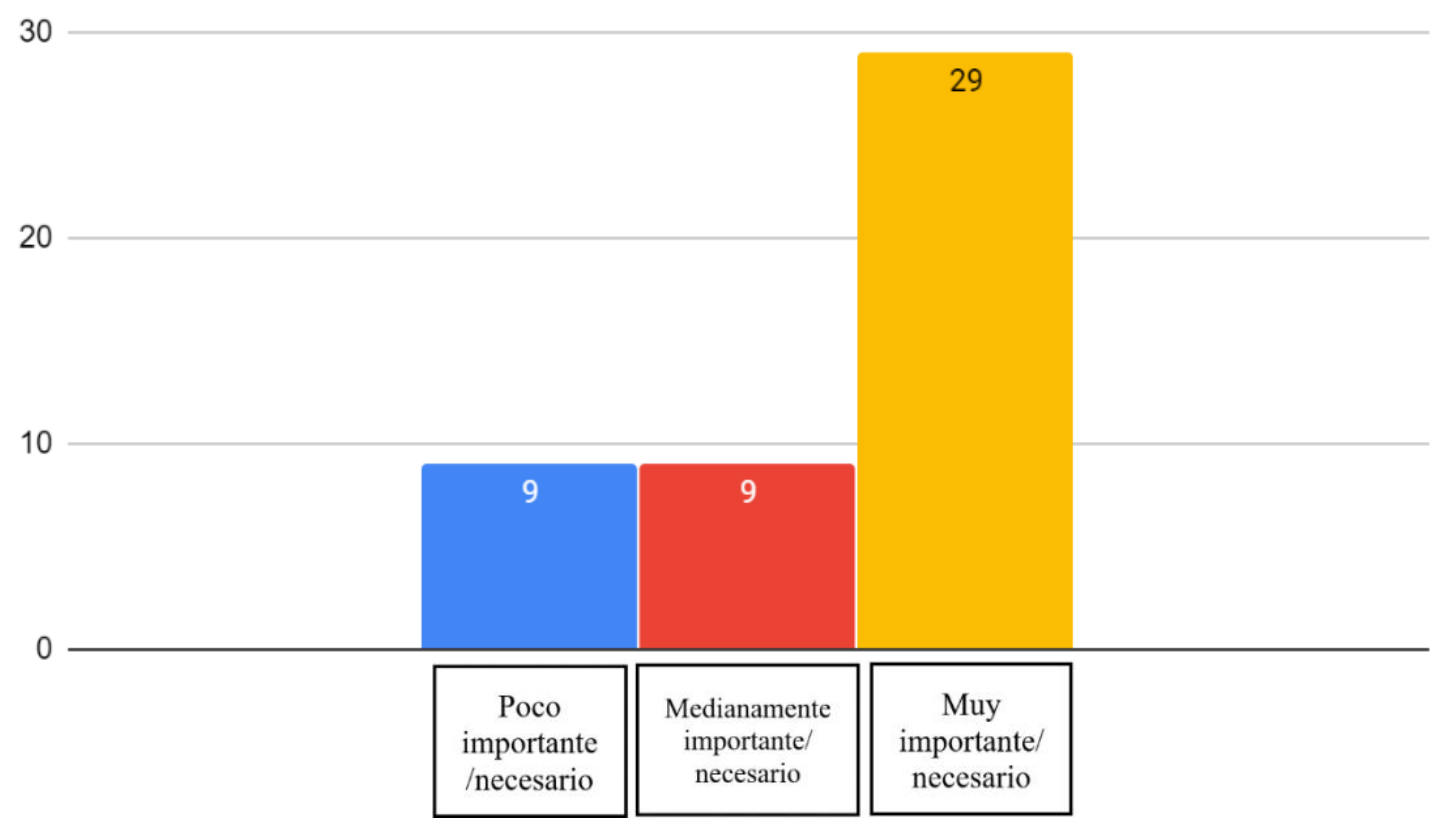

Cabe señalar, finalmente, que los resultados aquí mencionados permiten establecer vinculaciones con los postulados teóricos referidos al conectivismo, en especial en lo que atañe a las interrelaciones que ocurren entre los nodos (personas) al interior de redes virtuales que agrupan a distintas identidades intersubjetivas (Gutiérrez, 2002), (re)construyendo el saber y estableciendo puentes colaborativos a la hora de resolver problemáticas comunes (Hernández y Lizama, 2015). Otro aspecto importante tiene que ver con la comunicación, ámbito valorado por los/las estudiantes, ya que mediante esta es posible mantener un canal informativo fluido y constante que les permite a ambos agentes sostener procesos de enseñanza y aprendizaje efectivos, aun en contextos de distanciamiento social.

\subsection{DATOS DE CARÁCTER CUALITATIVO}

La encuesta incluyó dos preguntas abiertas, vinculadas a cada una de las partes constitutivas del instrumento en cuestión. Respecto a la primera interrogante, referida a los aspectos a 
mejorar en la relación docente-estudiante, es posible identificar dos tendencias expresadas por los/las estudiantes. La primera agrupa una considerable cantidad de respuestas que se manifestaron conformes acerca de los componentes filo-afectivos desarrollados entre el/la docente y los/las estudiantes, valorando aquello como una cualidad que facilita el trabajo de los segundos, dada la posibilidad certera de comunicarse con el/la docente y resolver dudas y dificultades de la actividad a ejecutar.

No obstante, existe un segundo gran grupo de estudiantes que sugirió aspectos a mejorar, pero no de la relación docente-estudiante, sino que de la forma en que se están desarrollando las clases virtuales. En ese sentido, estos/as jóvenes sostuvieron que, ante el apremiante contexto socioeconómico generado por la pandemia, el/la docente debiera grabar su clase a modo de vídeo explicativo y compartirla previamente a la sesión de la clase virtual, de modo que la misma solo sea de carácter resolutivo de dudas puntuales y que así se evite que, al momento de explicar el contenido, algunas personas interrumpan constantemente al docente, confundiendo a los demás estudiantes.

En relación a la segunda pregunta abierta, la cual guarda relación con la elaboración por parte de los/las estudiantes de una opinión respecto a un aspecto positivo y negativo de la actividad desarrollada en un espacio virtual de aprendizaje, es posible identificar dos grandes conjuntos de respuestas entregadas por los/las estudiantes.

En relación a aquellos elementos que declararon como "positivos" (oportunidades), se destaca que los/las estudiantes valoraron de buena forma el hecho de que la actividad guardara concordancia con prácticas que posteriormente serán abordadas en la universidad, siendo atingentes a sus requerimientos como futuros estudiantes de educación superior. Asimismo, los/las estudiantes agradecieron que el docente colocara a su disposición todo el material necesario y respondiera las dudas que estos tuvieran, sobre todo a través de la mensajería instantánea de WhatsApp.

Ahora bien, y en relación a aquellos aspectos que los/las estudiantes declararon como "negativos" (falencias), se manifestaron dos tendencias claras al respecto. La primera apunta al hecho de que, ante el envío de muchas actividades académicas de manera simultánea por parte de distintas asignaturas, la calidad de los trabajos resultantes no es la más óptima y, de 
modo colateral, se incrementan los niveles de estrés de los/las estudiantes. La segunda tendencia se relaciona con lo mencionando anteriormente respecto al contexto socioeconómico causado por el COVID-19: algunos/as estudiantes no poseen el acceso adecuado a internet ni los medios para conectarse de manera oportuna, no logrando comprender a cabalidad los objetivos de aprendizaje planteados por el docente y confundiéndose al momento de desarrollar las actividades.

\section{Conclusiones}

Para finalizar el presente artículo, conviene referirse brevemente a algunos aspectos que permiten sintetizar lo expuesto a lo largo del mismo. En primer lugar, a partir de lo expresado por los/las propios estudiantes, la realización conjunta por parte del docente de las actividades diseñadas por su persona se alza como un factor considerable a tomar en cuenta al momento de diseñar una actividad metodológicamente diferente, posibilitando con ello mayores niveles de motivación, de responsabilidad y de logro académico de los estudiantes en la ejecución de sus tareas.

En segundo lugar, lo anterior no es garantía de éxito si es que no va acompañado de sólidos puentes comunicativos y dialógicos entre el/la docente y los/as estudiantes, sobre todo en contextos de distanciamiento social y aprendizaje remoto. Si bien es cierto que la educación virtual no es algo nuevo, bien puede potenciarse si el/la docente transparenta los criterios evaluativos, define actividades de aprendizaje secuenciadas y se vale de herramientas y plataformas digitales para motivar a los/as estudiantes a continuar aprendiendo, pese a las adversidades externas al proceso en cuestión.

Finalmente, y en tercer lugar, aquella experiencia de aprendizaje virtual, procedimentalmente innovadora y tecnológicamente atractiva, no lograría mayor éxito académico si no existiera una sólida base humana sustentada en relaciones psicoafectivas cercanas entre estudiantes y docentes, en donde estos/as últimos/as resguarden el "deseo de aprender" de los primeros, así como sus fortalezas y capacidades a la hora de superar las dificultades que pudieran tener dentro y fuera de la escuela. 
De esta manera, es posible reafirmar el carácter experimental y empírico del presente trabajo, asumiendo los desafíos que quedan pendientes respecto a la educación virtual en el sistema educacional chileno, aunque relevando la importancia de cultivar, potenciar y preservar relaciones humanas sólidas y de calidad entre docentes y estudiantes, aspecto fundamental en el proceso de enseñanza y aprendizaje escolar.

\section{Referencias}

Anderson, E. (2004). What is strengths-based education? A tentative answer by someone who strives to be a strengths-based educator. Recuperado de https://www.coursehero.com/file/46797433/1-WhatisStrengths-BasedEducationpdf/

Bandura, A. (1987). Pensamiento y acción, fundamentos sociales. Barcelona: Ediciones Martínez Roca.

Carbonero, M. M.-A. y Reoyo, N. (2011). El docente estratégico como favorecedor del clima de aula. European Journal of education and Psychology, 4(2), 133-142.

Cerasoli, C., Nicklin, J. y Ford, M. (2014). Intrinsic motivation and extrinsic incentives jointly predict performance: a 40-year meta-analysis. Psychological bulletin, 140(4), 980-1008.

Claro, M., Nussbaum, M., López, X. y Díaz, A. (2013). Introducing 1 to 1 in the classroom: a large-scale experience in Chile. Journal of Educational Technology \& Society, 16(3), 315-328.

Claro, M., Preiss, D., San Martín, E., Jara, I., Hinostroza, J., Valenzuela, S. y Nussbaum, M. (2012). Assessment of 21st century ICT skills in Chile: test design and results from high school students. Computers \& Education 59(3), 1024-1053. 
REVISTA SABERES EDUCATIVOS, Nº 5, JULIO-DICIEMBRE 2020

Contreras, J. y Sepúlveda, C. (2015). El modelaje como fuente de aprendizaje. Ficha VALORAS actualizada de la 1ra. Edición El modelaje según Bandura (2003). Santiago, Chile: Centro de Recursos VALORAS-UC.

Del Mastro, C. (2005). Enseñanza estratégica en un contexto virtual. Un estudio sobre la formación de tutores en educación continua. (Tesis doctoral). Universidad Autónoma de Barcelona, España.

Duart, J. y Sangrá, A. (2000). Aprender en la virtualidad. Barcelona, España: Ediuoc-Gedisa Editorial.

Durán, G. y Kremerman, M. (2019). Los bajos salarios de Chile, análisis de la encuesta CASEN 2017. Santiago, Chile: Fundación Sol.

Gattavara, F. (26 de Febrero de 2020). OCDE: Acceso a internet en Chile subió "sustancialmente" a 87,5\% de los hogares. El Mercurio, p.20.

Gutiérrez, L. (2002). Conectivismo como teoría de aprendizaje: conceptos, ideas y posibles limitaciones. Revista Educación y Tecnonología, (1), 111-122.

Hernández, M. y Lizama, A. (2015). Constructivismo y conectivismo: factor clave para la enseñanza en entornos virtuales. Signos Universitarios Anejo, 2, 27-39.

Hernández, S. (2008). El modelo constructivista con las nuevas tecnologías: aplicado en el proceso de aprendizaje. Comunicación y construcción del conocimiento en el nuevo espacio tecnológico. Revista de Universidad y Sociedad del Conocimiento (RUSC), $5(2), 26-35$.

Jaramillo, C., y Chávez, J. (2015). TIC y educación en Chile: una revisión sistemática de la literatura. Nuevas Ideas en Informática Educativa - TISE, 221-231.

La evolución del coronavirus en tiempo real. (20 de mayo de 2020). Diario Sanitario. Recuperado de: https://diariosanitario.com/coronavirus-tiempo-real/ 
López, V., Bilbao, M. y Rodríguez, J. (2012). La sala de clases sí importa: incidencia del clima de aula sobre la percepción de intimidación y victimización entre escolares. Universitias Psychologica, 11(1), 91-101.

Mena, I., Jáuregui, P. y Moreno, A. (2011). Cada quien pone de su parte. Conflictos en la escuela. México: SM Ediciones.

Ministerio de Educación (2019). Programa de Estudio Educación Ciudadana $4^{\circ}$ medio. Santiago, Chile: Unidad de Currículum y Evaluación.

Ministerio de Educación. (2020). Orientaciones para docentes y equipos directivos para guiar el aprendizaje de los estudiantes a distancia. Santiago: Mineduc.

Ministerio de Desarrollo Social (2019). Principales datos entregados por el diagnóstico de la Mesa $N^{\circ} 16$ sobre integración digital. (Compromiso País-SUBTEL). Recuperado de http://www.compromisopais.cl/detalle_multimedia/7

Muñoz, C., Conejeros, M., Contreras, C. y Valenzuela, J. (2016). La relación educadoreducando: algunas perspectivas actuales. Estudios Pedagógicos, Número Especial 40 años, 75-89.

Radovic, P. (4 de abril de 2020). Sin internet, a pulso: Los escolares que se quedan atrás. La Tercera: https://www.latercera.com/la-tercera-domingo/noticia/sin-internet-a-pulsolos-escolares-que-se-quedan-atras/WO5U2DKM4VFI3INQCXLBMLQHNI/

Siemens, G. (2004). A learning theory for the digital age. Recuperado de http://www.elearnspace.org/Article/commectivism.htm

Spencer, B. (2004). On-line adult learning. En Griff Foley (ed.). Dimensions of adult learning: adult education and training in a global era (pp. 182-200). Berkshire: Open University Press.

Viau, R. (2009). La motivation en contexte scolaire. Bruxelles: De Boeck. 
REVISTA SABERES EDUCATIVOS, № 5, JULIO-DICIEMBRE 2020

Wood, D., Bruner, J. y Ross, G. (1976). The role of tutoring in problem solving. Journal of Child Psychology and Psychiatry, 17, 89-100. https://doi.org/10.1111/j.1469$\underline{7610.1976 . t b 00381 . x}$ 